\title{
Why is That Chin Numb? A Case of Burkitt's Lymphoma Presenting as Numb Chin Syndrome
}

\author{
Sejal Neel ${ }^{1}$, Abhi Chand Lohana ${ }^{2}$, Zainab Abbasi ${ }^{3}$, Marcos Madeiro ${ }^{4}$ \\ 1. Medicine, Liaquat University of Medical and Health Sciences, Jamshoro, PAK 2. Surgery, Jinnah Sindh Medical \\ University, Karachi, PAK 3. Internal Medicine, Liaquat University of Medical and Health Sciences, Jamshoro, PAK 4. \\ Internal Medicine, Bronson Methodist Hospital, Kalamazoo, USA
}

Corresponding author: Sejal Neel, sejal.neel@hotmail.com

\begin{abstract}
We report a case of numb chin syndrome (NCS) that preceded the diagnosis of Burkitt's lymphoma (BL) and discuss our findings with emphasis on metastatic malignancies in general and BL in particular causing NCS. A 73-year-old woman presented with worsening right-sided back pain for a week along with right-sided leg weakness and a progressive thigh and perianal numbness. She reported numbness of the chin which started two weeks prior. MRI showed compression of the cauda equina which was highly suggestive of neoplastic process. After debulking mass surgery, biopsy of the tissue from spine revealed BL. The patient received a round of radiotherapy of spine and multiple rounds of chemotherapy. Six months later she had reoccurrence of lymphoma with metastasis and eventually passed away. Presence of NCS in the setting of an underlying malignancy indicates very poor prognosis. In appropriate clinical setting, NCS should trigger work up for an underlying malignancy.
\end{abstract}

Categories: Internal Medicine, Oncology, Hematology

Keywords: numb chin, burkitt's lymphoma

\section{Introduction}

The numb chin syndrome (NCS) is a rare neurological condition characterized by localized numbness and prickling sensation in the skin of the chin and lower lip, limited to the region served by the mental nerve [1]. The first case of this syndrome was introduced in 1830 by Charles Bell [2]. NCS is mostly caused by infiltration or compression of mental nerve by dental disease but the rare and more important causes include the metastasis of distant tumor such as breast cancer and lymphomas. This syndrome may be the first symptom of underlying malignancy or the first sign of recurrence and metastasis in patients with preexisting cancer. NCS has also been associated with other systematic diseases such as diabetes and multiple sclerosis. It usually presents unilaterally, but bilateral manifestations have also been reported [1].

Received 08/19/2020 Review began $08 / 24 / 2020$ Review ended 08/25/2020 Published 09/04/2020

\section{(c) Copyright 2020}

Neel et al. This is an open access article distributed under the terms of the Creative Commons Attribution License CC-BY 4.0., which permits unrestricted use, distribution, and reproduction in any medium, provided the original author and source are credited.
Burkitt's lymphoma (BL) is a type of B-cell non-Hodgkin lymphoma that most commonly arise from chromosomal translocation of C-myc gene from chromosome 14 to chromosome 8 leading to over expression of MYC protein and increased proliferation of B-cells [3]. Some 1\%-5\% of all non-Hodgkin lymphomas are BL. Patients clinically present with bulky extra nodal disease, bone marrow infiltration, and central nervous system involvement [4].

\section{Case Presentation}

A 73-year-old woman with past medical history of hypertension, hyperlipidemia, and hypothyroidism presented with chief complaint of worsening low right-sided back pain for one week. She had not had any trauma or injury to the area prior to onset of pain. She then developed right-sided leg weakness, right thigh numbness, and perianal numbness in a progressive fashion. She also reported urinary retention.

On further questioning, she reported numbness of chin on both sides which started two weeks prior. She did have a left molar tooth extraction one week prior to the onset of all symptoms, and did receive local anesthesia for that. However, she confirmed that the numbness of chin was present prior to tooth extraction as well.

Her vital signs at the time of presentation were: blood pressure $124 / 58 \mathrm{mmHg}$, heart rate 89 beats $/ \mathrm{min}$, temperature $98.3^{\circ} \mathrm{F}$, and respiratory rate 22 breaths/min with oxygen saturation of $95 \%$ on room air. Her physical exam was significant for tenderness to palpation of lower lumbar spine, decreased motor strength, and sensation of the right lower extremity. She also had decreased sensation to touch and pain around her lips and on chin bilaterally.

Laboratory investigations at the time of presentation and on Day 4 and Day 5 are listed in Table 1. 


\section{Cureus}

\begin{tabular}{|c|c|c|c|c|}
\hline Test name & Day 0 & Day 4 & Day 5 & Reference range \\
\hline Serum sodium & $128(L)$ & 140 & 140 & $135-145 \mathrm{mmol} / \mathrm{L}$ \\
\hline Serum potassium & 4.7 & 4.3 & 4.5 & $3.5-5.3 \mathrm{mmol} / \mathrm{L}$ \\
\hline Serum chloride & 90 (L) & 107 & 107 & $98-108 \mathrm{mmol} / \mathrm{L}$ \\
\hline Serum bicarbonate & 20 (L) & 19 (L) & $17(L)$ & 23-32 mmo/L \\
\hline Serum creatinine & $1.39(\mathrm{H})$ & $1.24(\mathrm{H})$ & 0.97 & $0.60-1.10 \mathrm{mg} / \mathrm{dL}$ \\
\hline Estimated glomerular filtration rate & 37 (L) & 42 (L) & 56 (L) & $>60 \mathrm{~mL} / \min$ \\
\hline Serum blood urea nitrogen & 17 & $36(\mathrm{H})$ & $24(\mathrm{H})$ & $8-23 \mathrm{mg} / \mathrm{dL}$ \\
\hline Serum calcium & $10.6(\mathrm{H})$ & $8.4(L)$ & 8.9 & $8.6-10.3 \mathrm{mg} / \mathrm{dL}$ \\
\hline Serum phosphorus & & 3.7 & $2.6(L)$ & $2.7-4.5 \mathrm{mg} / \mathrm{dL}$ \\
\hline Serum magnesium & & 2.0 & $1.6(L)$ & $1.7-2.8 \mathrm{mg} / \mathrm{dL}$ \\
\hline Serum alkaline phosphatase & & 59 & 64 & 39-190 U/L \\
\hline Serum albumin & & $2.8(L)$ & $3.0(\mathrm{~L})$ & 3.5-5.0 g/dL \\
\hline Serum uric acid & & $21.2(\mathrm{H})$ & $10.9(H)$ & $2.5-8.0 \mathrm{mg} / \mathrm{dL}$ \\
\hline Serum aspartate aminotransferase & & $70(H)$ & $88(H)$ & $0-37 \mathrm{U} / \mathrm{L}$ \\
\hline Serum alanine aminotransferase & & 23 & 32 & 6-37 U/L \\
\hline Serum lactate dehydrogenase & & $1,906(H)$ & $2,114(\mathrm{H})$ & $94-250 \mathrm{U} / \mathrm{L}$ \\
\hline C-Reactive protein & & $101.4(\mathrm{H})$ & & $<6.0 \mathrm{mg} / \mathrm{L}$ \\
\hline Serum lactic acid & 2.4 & & & $0.7-2.5 \mathrm{mmol} / \mathrm{L}$ \\
\hline White blood cell count & 6.9 & 6.6 & 7.6 & $4.0-11.010^{* 9} / \mathrm{L}$ \\
\hline Red blood cell count & 4.41 & $3.02(L)$ & $3.27(L)$ & $4.2-5.510^{*} 12 / \mathrm{L}$ \\
\hline Hemoglobin & 13.0 & $9.1(L)$ & $9.7(L)$ & $12.0-16.0 \mathrm{~g} / \mathrm{dL}$ \\
\hline Platelet count & 157 & $128(L)$ & $138(L)$ & $140-44010^{0 * 9 / L}$ \\
\hline Haptoglobin & & $238(\mathrm{H})$ & & $30-200 \mathrm{mg} / \mathrm{dL}$ \\
\hline Eyythrocyte sedimentation rate & 22 & $39(\mathrm{H})$ & & $<30 \mathrm{~mm} / \mathrm{h}$ \\
\hline D-Dimer & & $1.21(\mathrm{H})$ & & $<0.5 \mathrm{ug} / \mathrm{mL}$ [FEU] \\
\hline Fibrinogen & & 425 & & $200-450 \mathrm{mg} / \mathrm{dL}$ \\
\hline Schistocytes & & None seen & & None seen [ [HPF] \\
\hline Prothrombin time & 11.7 & 10.9 & & $10.5-13.0 \mathrm{~s}$ \\
\hline Intermational normalized ratio & 1.0 & 0.9 & & N/A \\
\hline Hepatitis A IgM & & Negative & & Negative \\
\hline Hepatitis B surface antigen & & Negative & & Negative \\
\hline Hepattitis B surface antibody & & $<3.5($ L) & & $>11.4 \mathrm{m[UU} / \mathrm{mL}$ \\
\hline Hepatitis B core antibody & & Negative & & Negative \\
\hline Hepatitis B core IgM & & Negative & & Negative \\
\hline Hepatitis C antibody & & Negative & & Negative \\
\hline HIV-1/HIV-2 antibody & & Negative & & Negative \\
\hline
\end{tabular}

TABLE 1: Blood laboratory investigation on day of admission (Day 0), Day 4, and Day 5. 


\section{Cureus}

She had a CT scan of lumbar spine without contrast which showed multilevel chronic changes without any acute pathology. She underwent a CT myelogram of the lumbar spine, which also did not show any acute pathology.

She then underwent MRI of the thoracic and lumbar spine with and without IV contrast, which showed extensive epidural and possibly subdural enhancement at multiple levels of canal. A lesion within the canal at L2 level was causing severe compression of the cauda equina just below the level of conus and extending into the right foramen at L2-3. These findings were highly suggestive of a neoplastic process (Figure 1).

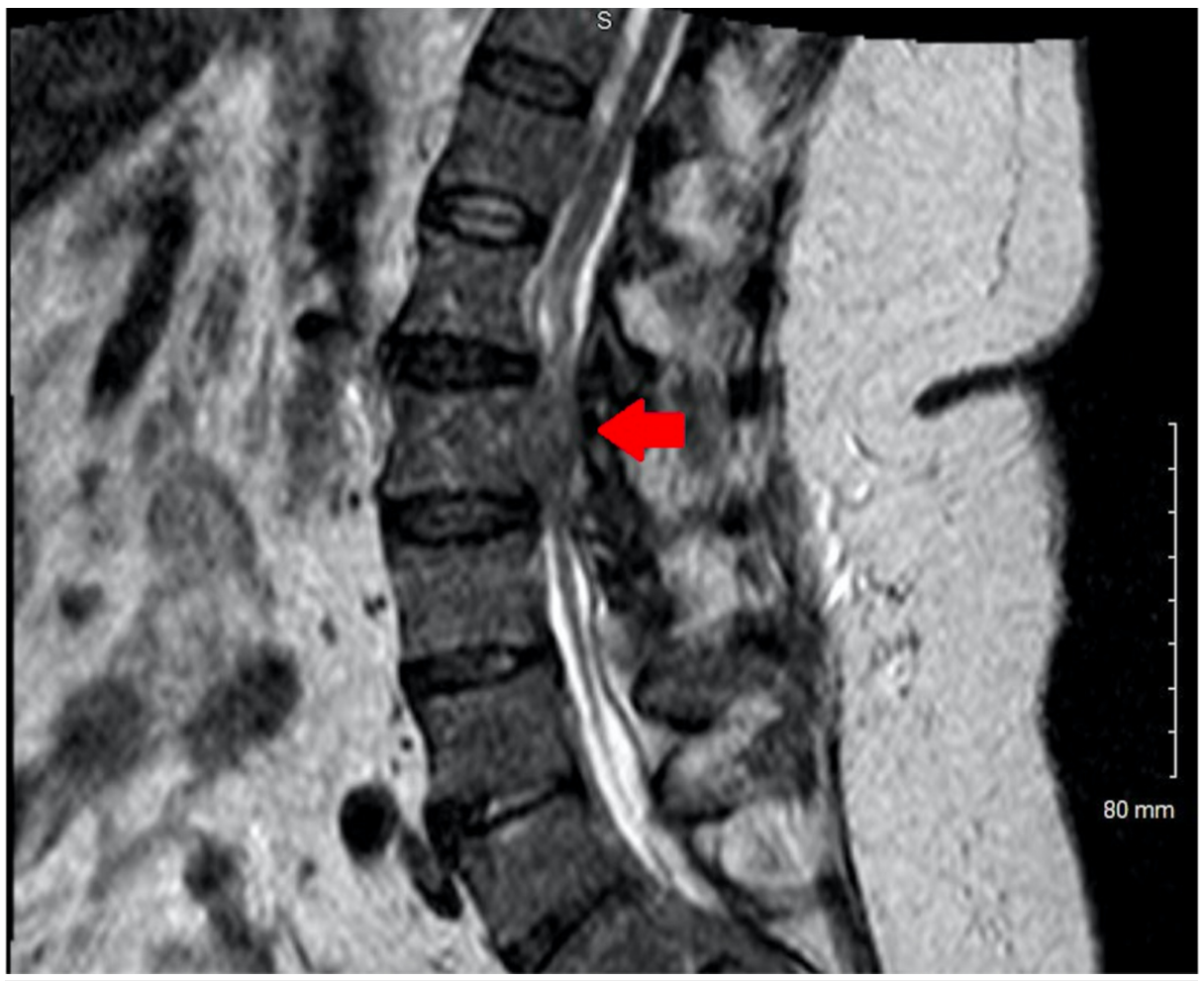

\section{FIGURE 1: MRI lumbar spine - lesion (red arrow) at L2 level causing} compression of cauda equina.

The patient was admitted to the hospital with the diagnosis of cauda equina syndrome. Neurosurgery was consulted, and she went to operating room emergently and underwent L1-3 laminectomy and de-bulking of the mass. The tissue was sent to pathology and cultures. While pathology of the mass was pending, the patient had a urinary catheter placed for her urinary retention. She also had acute kidney injury at the time of presentation which was thought to be multifactorial. Her creatinine level went up over the next two days, but later on normalized with IV fluids.

Biopsy of the tissue from the spine revealed BL with cytogenetics showing 8;14 translocation. Furthermore, cultures from the same tissue grew methicillin resistant staphylococcus aureus (MRSA).

Oncology was consulted at this time and the patient underwent further imaging to evaluate the extent of cancer burden with CT scan of neck, chest, abdomen, and pelvis. She was noted to have involvement of terminal ileum. She also underwent bone marrow biopsy which showed high grade B-cell lymphoma. She was started on rasburicase for elevated uric acid and prevention of tumor lysis syndrome. Oncology team recommended urgent initiation for treatment of BL. Lumbar puncture was performed for intrathecal administration of methotrexate (MTX), but needle could not be placed in ideal position after multiple attempts. However, small amount of cerebrospinal fluid (CSF) was collected, which eventually was positive for high grade lymphoma. Further results of CSF analysis are shown in Table 2. 


\section{Cureus}

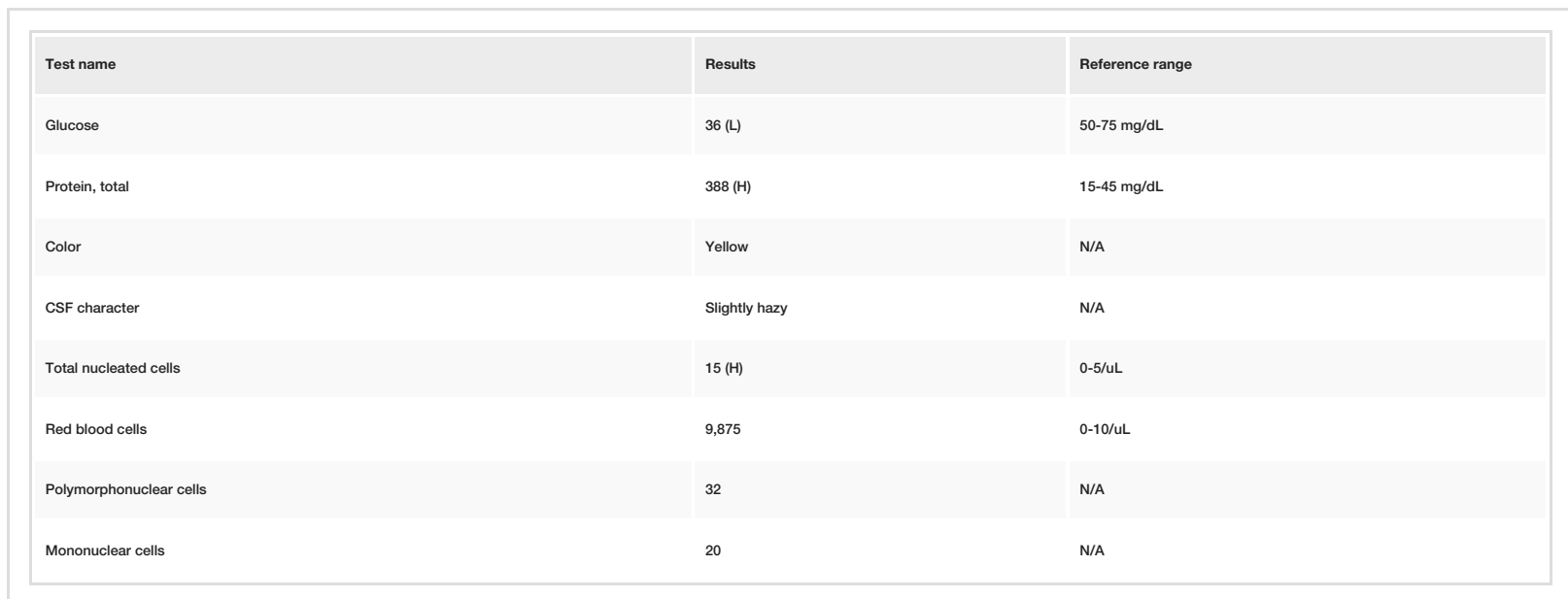

TABLE 2: CSF analysis.

CSF, cerebrospinal fluid

Infectious Diseases was consulted given the presence of MRSA in tissue cultures. Even though, she did not have any signs of infection negative blood cultures, she was started on IV vancomycin given her immunocompromised state due to lymphoma currently and chemotherapy later.

Given the complexity of the patient's clinical status and potential complications of the treatment of BL, the patient was transferred to a quaternary hospital for further management and treatment.

After transfer to the quaternary hospital, the patient received five treatments of radiation therapy to spinal lesions and one cycle of R-CHOP (Rituximab, Cyclophosphamide, Hydroxydaunomycin, Oncovin, Prednisolone) chemotherapy. She received three doses of MTX and two doses of cytarabine intrathecally in regular intervals after placement of an Ommaya reservoir. She also received one cycle of R-EPOCH (Rituximab, Etoposide, Prednisolone, Oncovin, Cyclophosphamide, Hydroxydaunorubicin) therapy. She continued to receive rasburicase with improvement in uric acid levels. IV vancomycin was continued for a total of two weeks. Furthermore, she received appropriate bacterial, viral, and fungal prophylaxis and bone marrow stimulating agents due to chemotherapy.

After one month of prolonged hospitalization, she was then discharged to a rehabilitation center with scheduled weekly alternate intrathecal MTX and cytarabine. She continued to stay in a rehabilitation center and received multiple rounds of intrathecal MTX and cytarabine as well as more cycles of R-EPOCH chemotherapy.

Five months later she was admitted to the hospital due to sepsis secondary to a urinary tract infection and severe encephalopathy. At that time she was found to have new renal masses consistent with relapse of the lymphoma. During that admission, she was given comfort care and passed away.

\section{Discussion}

Numb chin syndrome most frequently occurs due to odontogenic causes [5]. These causes range from local trauma, fractures, cysts, or osteomyelitis of the mandible and dental abscesses. It had also been seen to be present in systemic infections and inflammatory diseases such as HIV, syphilis, Lyme disease, sarcoidosis, multiple sclerosis, systemic lupus erythematosus, scleroderma, etc. [6]. However, the significance of this syndrome is due to its association with malignancies which was first reported by Calverley and Mohnac, who reported five cases in which NCS was the initial presentation for an underlying metastatic malignant disease [7]. NCS has been associated with hematological as well as with solid malignancies. It is most commonly associated with metastatic breast cancer and lymphoma, followed by prostate cancer, lung cancer, and leukemia [8]. In a retrospective study of patients with NCS, breast cancer comprised $64 \%$ of the primary tumors, and lymphoproliferative neoplasms comprised 14\% [9].

Numb chin syndrome related to malignancy can either be unilateral or bilateral [9]. But more cases of bilateral NCS are associated with hematological malignancies than with solid malignancies. BL in particular is associated with bilateral NCS [8]. In the present case, the patient also had bilateral numbness of the chin and after the diagnosis of BL it was concluded that NCS was related to it. In addition to the timing of onset of numbness in our case, bilateral involvement also excluded the possibility of its relation to recent dental procedure and associated left-sided local anesthesia. Furthermore, NCS precedes a diagnosis of malignancy in up to $47 \%$ of cases [10] and is usually the first manifestation in hematological malignancies in 
general and BL in particular [8]. In our case, even though the patient presented with clinical manifestation of cauda equine syndrome related to mass compression of spinal cord, chronologically the numbness of chin was the first symptom.

Majority of cases arising from neoplastic etiologies can be explained by either local compression or neoplastic infiltration of the mental or inferior alveolar nerves [11]. However, pathophysiology of NCS in relation to distant malignancies such as lymphoma has not been completely understood. It is plausible that in cases of distant neoplasms, it may be related to hematogenous, lymphatogenous, or even leptomeningeal spread. In a review of 36 patients with NCS, Lossos and Siegal reported 50\% of the patients had mandibular metastases, $14 \%$ base-of-skull bone lesions, and $22 \%$ leptomeningeal seeding. The patients with leptomeningeal seeding had malignant cells in the CSF and otherwise normal evaluations [9]. Of note, Raaphorst and Vanneste reported a case of numb cheek syndrome as the anti-Hu paraneoplastic neuronopathy [12], hinting that NCS may also carry similar paraneoplastic or autoimmune pathogenesis. Moreover in some cases the cause may not be found at all as in the review by Lossos and Siegal, where the cause was unknown in $11 \%$ of patients [9]. In our patient, NCS most likely happened as a result of leptomeningeal spread given the presence of neoplastic cells in the CSF and evidence of neoplastic process on multiple epidural and subdural levels on MRI.

The presence of NCS in association with the malignancy carries a poor prognosis. Its occurrence in patients with malignancy is indicative of metastasis, with a reported overall mortality of $79 \%$ and a weighted mean survival of approximately seven months [13]. Our patient passed away approximately six months after the diagnosis of BL. It is crucial to view NCS as a warning sign that is indicative of a poor survival outcome when it is present in patients with underlying malignant diseases [14]. At the same time, NCS in the absence of any identifiable cause should raise suspicion for underlying malignancy and brain imaging should be pursued to look for metastasis. CT or an MRI of the brain may show metastatic brain lesions or even leptomeningeal involvement; however, MRI is considered superior to CT scan while evaluating the etiology of NCS [1].

\section{Conclusions}

Numb chin syndrome can be the first sign of underlying malignancy or recurrence of a malignancy. Its presence in the setting of an underlying malignancy indicates very poor prognosis as in this case. Clinicians should have a very high index of suspicion to diagnose NCS. Absence of any identifiable causes should trigger thorough workup for occult malignancy as NCS can be the initial symptom of malignancy.

\section{Additional Information \\ Disclosures}

Human subjects: Consent was obtained by all participants in this study. Conflicts of interest: In compliance with the ICMJE uniform disclosure form, all authors declare the following: Payment/services info: All authors have declared that no financial support was received from any organization for the submitted work. Financial relationships: All authors have declared that they have no financial relationships at present or within the previous three years with any organizations that might have an interest in the submitted work. Other relationships: All authors have declared that there are no other relationships or activities that could appear to have influenced the submitted work.

\section{References}

1. Algahtani H, Shirah B, Bassuni W, Adas R: Bilateral numb chin syndrome as the initial presentation of Burkitt's lymphoma/leukemia: a report of two cases and review of the literature. Case Rep Hematol. 2016, 2016:1-7.

2. Furukawa T: Charles Bell's description of numb chin syndrome. Neurology. 1988, 38:

3. Molyneux EM, Rochford R, Griffin B, et al.: Burkitt's lymphoma. Lancet. 2012, 379:1234-1244.

4. Oosten LEM, Chamuleau MED, Thielen FW, et al.: Treatment of sporadic Burkitt lymphoma in adults, a retrospective comparison of four treatment regimens. Ann Hematol. 2018, 97:255-266.

5. Lata J, Kumar P: Numb chin syndrome: a case report and review of the literature . Indian J Dent Res. 2010, 1:135-137.

6. Maeda K, Taniguchi J, Matsui K: Two cases of numb chin syndrome diagnosed as malignant disease . Oxford Med Case Rep. 2018, 2018:omy097.

7. Calverley Jr, Mohnac AM: Syndrome of the numb chin. Arch Intern Med. 1963, 112:819-821.

8. Sasaki M, Yamazaki H, Aoki T, Ota Y, Sekiya R, Kaneko A: Bilateral numb chin syndrome leading to a diagnosis of Burkitt's cell acute lymphocytic leukemia: a case report and literature review. Oral Surg Oral Med Oral Pathol Oral Radiol Endod. 2011, 111:e11-e16.

9. Lossos A, Siegal T: Numb chin syndrome in cancer patients: etiology, response to treatment, and prognostic significance. Neurology. 1992, 42:1181-1184.

10. Ryba F, Rice S, Hutchison IL: Numb chin syndrome: an ominous clinical sign . Br Dent J. 2010, 208:283-285.

11. Smith RM, Hassan A, Robertson CE: Numb chin syndrome. Curr Pain Headache Rep. 2015, 19:44.

12. Raaphorst J, Vanneste J: Numb cheek syndrome as the first manifestation of anti-Hu paraneoplastic neuronopathy. J Neurol. 2006, 253:664-665.

13. Gil SG, Diago MP, Diago MP: Malignant mental nerve neuropathy: systematic review. Medicina Oral, Patologia Oral y Cirugia Bucal. 2008, 13: 


\section{Cureus}

14. Friedrich RE: Mental neuropathy (numb chin syndrome) leading to diagnosis of metastatic mediastinal cancer. Anticancer Res. 2010, 30:1819-1821. 